Journal of Mathematics and Statistics 8 (1): 98-106, 2012

ISSN 1549-3644

(C) 2012 Science Publications

\title{
A Study on the Behavior of Volatility in Saudi Arabia Stock Market Using Symmetric and Asymmetric GARCH Models
}

\author{
${ }^{1}$ Ajab Al Freedi, ${ }^{2}$ Ahmed Shamiri and ${ }^{3}$ Zaidi Isa \\ ${ }^{1}$ School of Mathematical Sciences, University Kebangsaan Malaysia, 43600 Bangi Malaysia \\ ${ }^{2}$ Institute of Mathematical Sciences, University Malaya, Malaysia \\ ${ }^{3}$ Center for Modeling and Data Analysis (DELTA), School of Mathematical Sciences \\ University Kebangsaan Malaysia, 43600 Bangi, Selangor DE, Malaysia
}

\begin{abstract}
Problem statement: This study examines several stylized facts (heavy-tailedness, leverage effect and persistence) in volatility of stock price returns exploiting symmetric and asymmetric GARCH family models for Saudi Arabia. Approach: This study is carried out using closing stock market prices over 15 years covering the period 1 January 1994 to 31 March 2009. The sample period is divided into three sub-periods according to the local crisis in 2006. Results: The results reveal that asymmetric models with heavy tailed densities improve overall estimation of the conditional variance equation. Moreover, we find that AR (1)-GJR GARCH model with Student-t outperform the other models during and before the local crisis in 2006, while AR (1)-GARCH model with GED exhibits a better performance after the crisis. Furthermore, the findings reveal the existence of leverage effect at 1 percent significance level. Conclusion/Recommendations: Finally, the volatility persistent in the samples during and after crises decreases in all models under various distribution assumptions.
\end{abstract}

Key words: Volatility, fat tailedness, GARCH, asymmetric densities

\section{INTRODUCTION}

Saudi Arabia is one of the countries that is politically stable, acts as a leading force within the Gulf Cooperation Council (GCC) and plays an important role within the Organization of the Petroleum Exporting Countries (OPEC). Saudi stock market, with 111 listed companies, represents the largest stock market based on value of shares traded by sectors (1633.6 Billion Riyals, September 2008) in the Gulf region (Alkhathlan and Prabakaran, 2009). In December 2005, Saudi Arabia became a member of World Trade Organization (WTO). In 2009, the World Bank's Business conducted a survey regarding the ease of doing business and gave Saudi Arabia high rank scoring 16out of 181. As a result, International financial corporation has recently included the equity indices of Saudi Arabia in its emerging market database.

In Saudi Arabia, stock market was established in 1984. Here, one may note that from 1984 to 1989 , the stock market was relatively stable and no big fluctuations are observed in the stock returns. During 1990, the financial market received its first wave of shocks caused by Iraq's occupation of Kuwait. The market responds with a sharp decline causing the index to drop to 990 points corresponding to 1,188 points before the event. However, after the occupation, the index of the financial market started to rise again until 1998 and reached its highest level (2,351points) in 1992. The second shocking event was caused by the Asian financial crisis during 1997-1998. This crisis resulted in a decline to $1,313.6$ point in the index price. Turning to 2004-2007 period, interesting events emerge. First, the index price started at 4,432 point during year 2004 and increased sharply to 20,600 point in 2006, which represent highest level during the last 18 years and only lasted for one day (25th February 2006) before the index decline. This sharp increase in the index price could be due to the good news effects, such as the European Union approval of Saudi Arabia into WTO and the sharp increase in the oil price (\$70) in 2005. Secondly, the market index lost more than 10,554 points during a short period of time (from $26^{\text {th }}$ January 2006 to 1st May 2006), despite the continuous increase in oil price, which reached to $\$ 90$ in 2008 . By the end of 2008-2009, the stock market lost about 5,343 points where the price declined to the same level as in 2004.

\section{MATERIALS AND METHODS}

This short history of Saudi Arabia stock market closing price index (TSAI) emphasizes the importance 
of TSAI index in the Gulf countries and the financial investment opportunities for investors. In recent years, there has been increasing concern among researchers, practitioners and regulators over evaluating models of financial risk in emerging markets. Autoregressive moving-average (ARIMA) model, developed by Box and Jenkins (1994), assumes the conditional variance of the errors (uncertainty measure)is constant over time (homoscedaticity). However, as displayed in Fig. 1, the financial market evidence rejects this assumption. Moreover, the financial market exhibit some stylized facts such as leptokurtosis, volatility clustering and leverage effects which cannot be explained by ARMA models. ARMA models have shown their limitation in the modeling of high-frequency (weekly, daily or intradaily) data. It is assumed that only the mean response could be changing with covariates while the variance remains constant over time. Hence, it often revealed to be an unrealistic assumption in practice.

During the last few decades, we have seen a multitude of different suggestions for how to model the second moment, often referred to as volatility, of financial returns. Indeed, it is now widely accepted that high frequency financial returns are heteroskedastic. Among the models that have proven to be the most successful are the autoregressive conditional heteroskedasticity (ARCH) family of models introduced by Engle (1982) and Bollerslev (1986).

Despite the burgeoning interest in and evaluation of volatility, a clear consensus on which distribution and/or volatility model specification to use has not yet been reached even for finance practitioners and risk professionals. The importance of the standard GARCH model comes from its ability to capture some of the stylized facts of volatility such as volatility clustering which demonstrates that large changes tends to be followed by large changes and small changes tend to be followed by a small changes (Fig. 1 evidence from TSAI). Secondly, however, the model is unable capture the asymmetry of positive and negative returns (leverage effect) because of the dependence on the size of shocks rather than the sign of the shocks, Morimune (2007). Thus, the standard GARCH model does not take into account the effects of negative shocks on volatility more than the positive shock's which were observed by Black (1976). In addition, one of other limitations of standard GARCH models is that it does not fully capture the third styled fact, thickness tails (excess Kurtosis), that occurs on high frequency financial time series.

Considering the recent empirical evidence on volatility clustering, asymmetry and heavy-tailedness in financial return series, we are in the opinion that employing asymmetric volatility models assuming heavy-tailed densities in the maximum likelihood estimations contribute to the existing literature. To this end, the main aim of this study is to present the most favored GARCH family model and distribution hypotheses for risk managers as well as policy makers examining the Saudi Arabia stock market. The structure of the remainder of this study is as follows. We review the statistical evaluation of individual volatility models using the GARCH method and discuss the distribution specification for candidate volatility models. Data description, empirical results and model comparison are discussed and concludes the study.

Volatility models: As noted by Bera and Higgins (1993) and Daly (2008), there have been numerous applications of the GARCH family models since its introduction by Bollerslev (1986). Here, it is worth noting that various extensions of $\mathrm{GARCH}$ family models enter quick expansion phase. According to the ability to capture a stylized fact of asymmetry, GARCH family models can be divided into symmetric and asymmetric models. This common property refers to the fact that volatility of returns has various effects on positive and negative shocks. In addition, this fact has played an important role in the development of other sophisticated extensions of GARCH family models.
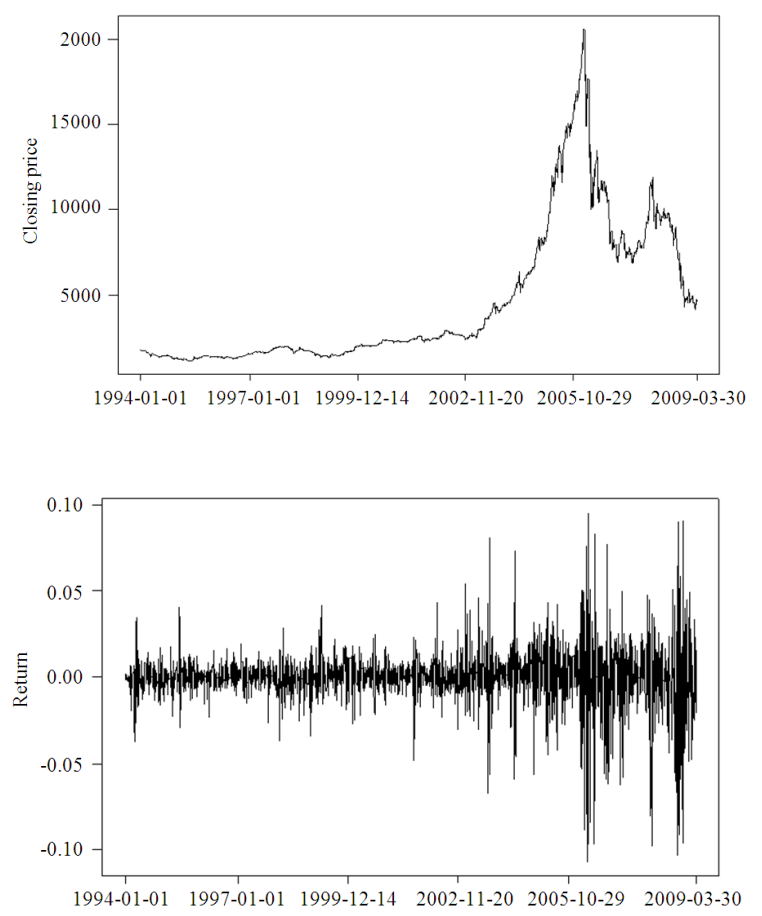

Fig. 1: Daily price and returns of TSAI for all period 
Symmetric GARCH model: The GARCH models allow the variance not only to be dependent on past shocks but also to be dependent on the most recent variance of itself. The GARCH model is given as follows Eq. 1:

$$
\sigma_{\mathrm{t}}^{2}=\omega+\sum_{\mathrm{i}=1}^{\mathrm{q}} \alpha_{\mathrm{i}} \varepsilon_{\mathrm{t}-\mathrm{i}}^{2}+\sum_{\mathrm{j}=1}^{\mathrm{p}} \beta j \sigma_{\mathrm{t}-\mathrm{j}}^{2}
$$

where, $\omega, \alpha_{\mathrm{i}}$ and $\beta_{\mathrm{j}}$ are non-negative constants

Although the standard GARCH model can capture several important phenomena in the financial time series, however, it is unable to capture other volatility properties such as heavy tailedness and leverage effects. For example, the model assumes that the effects of different shocks on volatility depend only on the size regardless of its sign. As shown in Eq. 1, the model depends on summation of square of shocks. It is well known that volatility is higher after negative shocks than after positive shocks of the same magnitude (bad news effects on volatility more than good news). This has led to the use of non-linear distribution to take into account that type of stylized fact. Such non-linear models are asymmetric GARCH models (for example, EGARCH and GJR-GARCH).

Asymmetric EGARCH model: Nelson (1991) introduces the EGARCH model to overcome the weakness of standard GARCH in terms of the leverage effect and parameter restrictions. As mentioned above, this model successfully accounts for the sign of shocks. The model is given as follows Eq. 2:

$\operatorname{In}\left(\sigma_{\mathrm{t}}^{2}\right)=\omega+\sum_{\mathrm{j}=1}^{\mathrm{p}} \alpha_{\mathrm{i}} \frac{\left|\varepsilon_{\mathrm{t}-\mathrm{i}}\right|+\lambda_{\mathrm{i}} \varepsilon_{\mathrm{t}-\mathrm{i}}}{\sigma_{\mathrm{t}-\mathrm{i}}}+$

$\sum_{\mathrm{j}=1}^{\mathrm{q}} \beta_{\mathrm{j}} \operatorname{In} \sigma_{\mathrm{t}-\mathrm{j}}^{2}$

Note that when $\varepsilon_{\mathrm{t}-\mathrm{i}}$ is positive or there is 'good news', the total effect of $\varepsilon_{\mathrm{t}-\mathrm{i}}$ is $\left(1+\lambda_{\mathrm{i}}\right)\left|\varepsilon_{\mathrm{t}-\mathrm{i}}\right|$; in contrast, when $\varepsilon_{\mathrm{t}-\mathrm{i}}$ is negative or there is 'bad news', the total effect of $\varepsilon_{\mathrm{t}-\mathrm{i}}$ is $\left(1-\lambda_{\mathrm{i}}\right)\left|\varepsilon_{\mathrm{t}-\mathrm{i}}\right|$. This model shows that large shocks have greater impact on volatility than the standard GARCH model. If the leverage effect exists, we expect it to be negative.

Asymmetric GJR-GARCH model: GJR-GARCH model which was proposed by Glosten et al. (1993), offers an alternative method to allow for asymmetric effect of positive and negative socks on volatility. It's given by Eq. 3:

$$
\begin{aligned}
& \sigma_{\mathrm{t}}^{2}=\omega+\sum_{\mathrm{i}=1}^{\mathrm{q}} \alpha_{\mathrm{i}} \varepsilon_{\mathrm{t}-\mathrm{i}}^{2}+\sum_{\mathrm{j}=1}^{\mathrm{p}} \lambda \mathrm{S} \overline{\mathrm{t}}-\mathrm{i} \varepsilon_{\mathrm{t}}^{2}+ \\
& \sum_{\mathrm{j}=1}^{\mathrm{q}} \beta_{\mathrm{j}} \sigma_{\mathrm{t}-\mathrm{j}}^{2}
\end{aligned}
$$

where $\mathrm{S} \overline{\mathrm{t}}$ is a dummy variable:
Table 1: Descriptive statistics of TSAI return

\begin{tabular}{lllll}
\hline & Before crisis & During crisis & After crisis & Whole sample \\
\hline Min & -0.0675 & -0.1071 & -0.1033 & -0.1071 \\
Max & 0.081 & 0.0953 & 0.0909 & 0.0953 \\
Mean & 0.0004 & 0.0001 & -0.0008 & 0.0002 \\
Med & 0.0004 & 0.0003 & 0.001 & 0.0004 \\
St. dev & 0.0081 & 0.0216 & 0.0225 & 0.0134 \\
Skew & -0.0252 & -0.8283 & -0.6923 & -1.0027 \\
Kurt & 13.516 & 4.2449 & 4.6063 & 13.1496 \\
Q 20 & 88.352 & 65.786 & 42.394 & 157.98 \\
& {$[0.000]$} & {$[0.000]$} & {$[0.002]$} & {$[0.000]$} \\
Q $^{2} 20$ & 1644.9 & 722.12 & 368.2 & 5402 \\
& {$[0.000]$} & {$[0.000]$} & {$[0.000]$} & {$[0.000]$} \\
J.Bera & 24123.1 & 648.47 & 421.55 & 32285 \\
& {$[0.000]$} & {$[0.000]$} & {$[0.000]$} & {$[0.000]$} \\
ARCH (2) & 383.616 & 77.097 & 40.865 & 596.323 \\
& {$[0.000]$} & {$[0.000]$} & {$[0.000]$} & {$[0.000]$} \\
No. Obs. & 3180 & 761 & 449 & 4390
\end{tabular}

Figures in square bracket denote p-values. J. Bera is the Jarque-Bera test for normality, $\mathrm{Q}^{2}(20)$ is the Ljung-Box test for squared returns and ARCH (2) is the Engle's Lagrange Multiplier test for conditional heteroskedasticity at lag 2. Before Crisis : Jan 1994.

$\mathrm{S} \overline{\mathrm{t}}=\left\{\begin{array}{c}1 \text { if } \varepsilon_{\mathrm{t}}<0 \\ 0 \text { if otherwise }\end{array}\right.$

Above formula declares that the impact of $\sigma_{t}^{2}$ on the conditional variance series $\left(\sigma_{\mathrm{t}}^{2}\right)$. In this model $\varepsilon_{\mathrm{t}}>0$ (bad news) and $\varepsilon_{\mathrm{t}}>0$ (good news) have different effects on conditional variance. If the leverage effect exists we expect it to be positive and the impulse is $\alpha+\lambda$.

Distribution assumption: Commonly, probability distribution of asset returns often exhibit fatter tails than the standard normal distribution. Volatility clustering accounts for some but not all of the fat tail effect (excess kurtosis). In addition, fat tail effect can also result from the presence non-Gaussian asset return distribution that just happen to have fat tails. The fat tail phenomenon is known as excess kurtosis. A time series that exhibit a fat tail distribution are often referred to leptokurtic distribution and in reality the returns are typically negatively skewed (Table 1). The probability density functions that can capture this phenomenon (fat tailedness and asymmetry) are Student-t and GED distribution.

Normal distribution: The Normal density function can be written as follows:

$$
f_{v}\left(\varepsilon t \backslash I_{t-1}\right)=\frac{\exp \left(-0.5 z_{t}^{2}\right)}{\sigma_{t} \sqrt{2 \pi}}
$$

The following log-likelihood function is maximized Eq. 4:

$$
\left.\mathrm{L}_{\text {normal }}=\frac{1}{2} \sum_{\mathrm{t}=1}^{\mathrm{T}}\left[\operatorname{In}(2 \pi)+\operatorname{In}\left(\sigma_{\mathrm{t}}^{2}\right)+\mathrm{z}_{\mathrm{t}}^{2}\right)\right]
$$

where, $\mathrm{T}$ is the number of observations. 

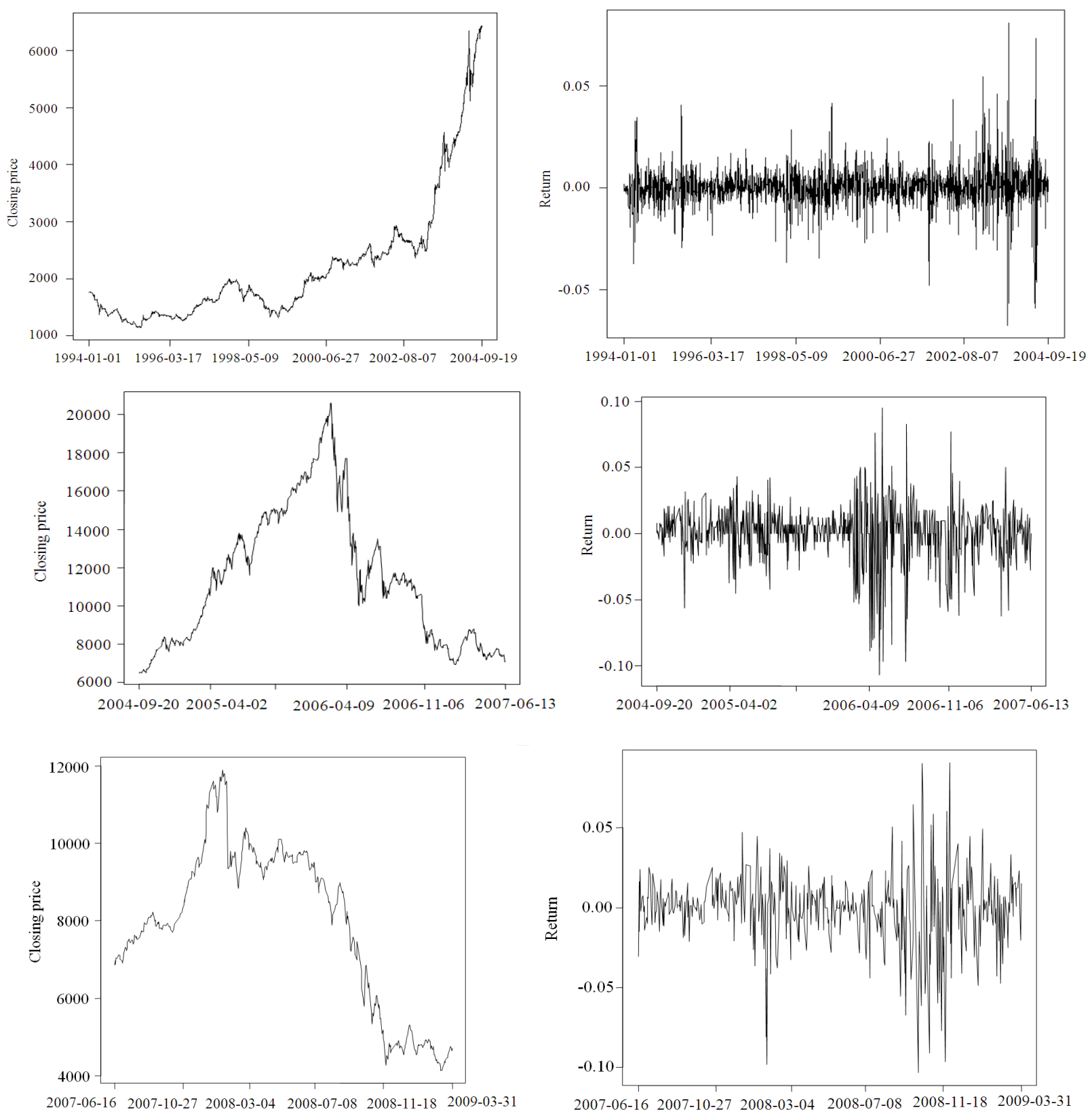

2007-06-16 2007-10-27 2008-03-04 2008-07-08 2008-11-18 2009-03-31

Fig. 2:From top to bottom, daily price and returns of TSAI for the periods of before, during and after the crisis

Student-t distribution: When the Student- $\mathrm{t}$ conditional density is considered, log-likelihood function can be specified as follows Eq. 5:

$$
\begin{aligned}
& \mathrm{L}_{\text {stud.t }}=\operatorname{In}\left[\Gamma\left(\frac{\mathrm{v}+1}{2}\right)\right]-\operatorname{In}\left[\Gamma\left(\frac{\mathrm{v}}{2}\right)\right]-0.5 \\
& \operatorname{In}(\mathrm{v}-2)-0.5 \sum_{\mathrm{t}=1}^{\mathrm{T}}\left[\operatorname{In} \sigma_{\mathrm{t}}^{2}+(1+\mathrm{v}) \operatorname{In}\left(1+\frac{\mathrm{z}_{\mathrm{t}}^{2}}{\mathrm{v}-2}\right)\right]
\end{aligned}
$$

where, $v$ is the degrees of freedom, $0<v \leq \infty$ and $\Gamma(\bullet)$ is the gamma function.

Generalized error distribution: Nelson (1991) Generalized Error Distribution (GED) recognizes that the kurtosis and skewness are necessary in financial time series. The following log-likelihood function is maximized assuming GED Eq. 6 :

$$
\mathrm{L}_{\mathrm{GED}}=\sum_{\mathrm{t}=1}^{\mathrm{T}} \operatorname{In}(\mathrm{v} / \lambda)-0.5\left|\frac{\mathrm{z}_{\mathrm{t}}}{\lambda}\right|^{v}
$$




$$
-\left(1+\mathrm{v}^{-1}\right) \operatorname{IN}(2)-\operatorname{In}[\Gamma(1 / \mathrm{v})]-0.5 \operatorname{In}\left(\sigma_{\mathrm{t}}^{2}\right)
$$

where, $-\infty<\mathrm{z}_{\mathrm{t}}<\infty, 0<\mathrm{v} \leq \infty$ and:

$$
\lambda=\sqrt{\frac{2\left(-\frac{2}{\mathrm{v}}\right) \Gamma(1 / \mathrm{v})}{\Gamma(3 / \mathrm{v})}}
$$

Data description: In this study, we use high-frequency data closing price (TSAI) of Saudi Arabia stock market index over the period, $1^{\text {st }}$ January 1994 to $31^{\text {th }} 2009$ consisting of total 4390 observations. Fig. 1 displays the behavior of the TSAI returns over the sample period. As shown in the Fig. 1, there is clear evidence of volatility clustering that is large or small asset price changes tend to be followed by other large or small price changes of either sign (positive or negative). This implies that stock return volatility changes over time. We divide the daily price index into three sub-periods, before crisis, which covers the period from $1^{\text {st }}$ January 1994 to $19^{\text {th }}$ September 2004 with 3180 observations, the crisis period which is from $20^{\text {th }}$ September 2004 to $13^{\text {th }}$ June 2007 with 761 observations and finally, after the crisis period that covers from $16^{\text {th }}$ June 2007 to $31^{\text {st }}$ March 2009 with 449 observations. The three subsample periods are shown in Fig. 2 which clearly displays the changes in volatility over time. This is the signal for volatility clustering. Hence, we investigate the volatility of returns for each sub-period. The returns are calculated as follows Eq. 7:

$$
\mathrm{Rt}=\operatorname{In}\left(\mathrm{p}_{\mathrm{t}} / \mathrm{p}_{\mathrm{t}-1}\right)
$$

Table 1 presents descriptive statistics on TSAI logreturns for the whole sample period as well as the three sub-periods. The daily return series presented in the table display positive mean return in two periods (before and during the crisis periods), but the mean is negative for the period after the crisis which could be explained by high volatility (see Fig. 2). The mean is close to zero for all periods under investigation. The returns for all periods are negatively skewed and the distributions of log-returns tend to be in the negative side. This indicates that in general that TSAI has more losses than gains; however the magnitude of these losses varies across periods. It is observed that higher losses occured during periods of crisis and after crisis as compared to before the crisis. The table also shows that for all periods the log-returns are leptokurtic, with a higher peak and fatter tails compared to the normal distribution. In general, normal skewness (0.00) and normal kurtosis (3.00) are rejected at the 5 percent significance level.
Engle (1982) ARCH LM test statistics are found to be highly significant for the estimated models in all periods considered in this study. This justifies the legitimacy of using GARCH family models. The test of normality by Jarque and Bera (1987) strongly rejects the normal distribution hypothesis. The Ljung Box Q statistic of order 20 on both returns and squared returns reflects a high serial correlation. Thus, it can be concluded that all series are non-normal and serially correlated. In the estimations, the presence of excess kurtosis necessitates fatter-tailed distributions such as Student- $t$ or skewed Student- $t$ rather than modeling with the normal distribution.

\section{RESULTS AND DISCUSSION}

Empirical results: This section analyzes the estimation results, the validity of the models and post estimation tests.

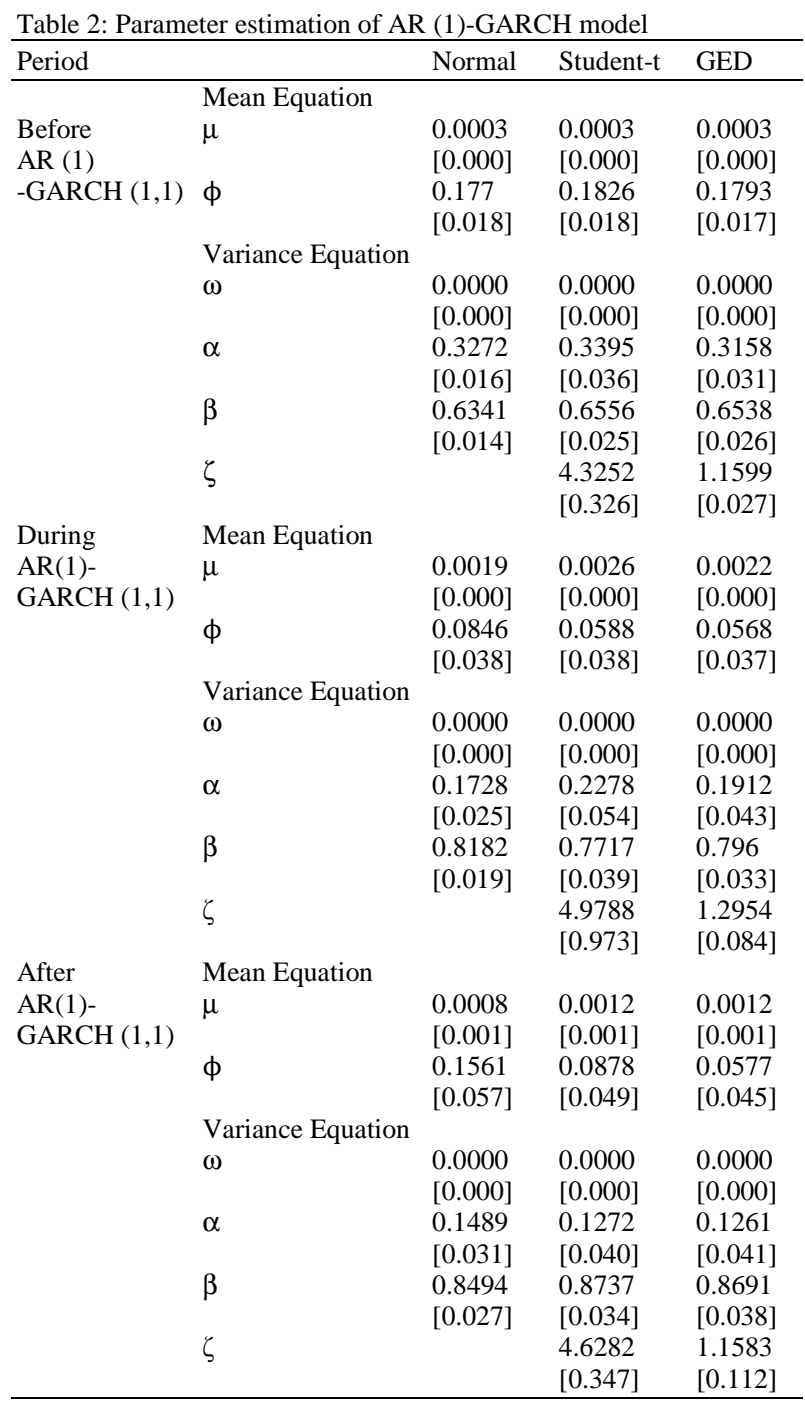

Figures in the square brackets are p-values 
J. Math. \& Stat., 8 (1): 98-106, 2012

Table 3: Model diagnostics of AR (1)-GARCH model

\begin{tabular}{|c|c|c|c|c|}
\hline Period & & Normal & Student- $\mathrm{t}$ & GED \\
\hline Before & Q (10) & 55.264 & 54.05 & 54.983 \\
\hline AR (1) & & {$[0.000]$} & {$[0.000]$} & {$[0.000]$} \\
\hline \multirow[t]{9}{*}{-GARCH $(1,1)$} & $Q^{2}(10)$ & 4.128 & 5.6076 & 4.9131 \\
\hline & & [0.941] & [0.847] & [0.897] \\
\hline & LM (10) & 4.2182 & 5.974 & 5.1564 \\
\hline & & [0.937] & {$[0.817]$} & {$[0.880]$} \\
\hline & $\mathrm{LM}^{2}(10)$ & 0.1847 & 0.225 & 0.2071 \\
\hline & & [1.000] & [1.000] & [1.000] \\
\hline & AIC & -23083.3 & -23523.7 & -23469.1 \\
\hline & BIC & -23052.9 & -23487.3 & -23432.7 \\
\hline & Log-L & 11546.6 & 11767.8 & 11740.5 \\
\hline During & Q (10) & 15.3075 & 15.0216 & 15.7213 \\
\hline $\operatorname{AR}(1)$ & & {$[0.121]$} & {$[0.1313]$} & [0.1079] \\
\hline \multirow[t]{9}{*}{-GARCH $(1,1)$} & $\mathrm{Q}^{2}(10)$ & 8.615 & 9.5392 & 9.1891 \\
\hline & & [0.569] & [0.482] & {$[0.5143]$} \\
\hline & LM (10) & 8.687 & 9.6467 & 9.2823 \\
\hline & & {$[0.562]$} & [0.472] & {$[0.505]$} \\
\hline & $\mathrm{LM}^{2}(10)$ & 1.9192 & 2.4693 & 2.1767 \\
\hline & & [0.997] & [0.991] & [0.995] \\
\hline & AIC & -4009.51 & -4058.94 & -4053.38 \\
\hline & BIC & -3986.43 & -4031.13 & -4025.57 \\
\hline & Log-L & 2009.87 & 2035.47 & 2032.69 \\
\hline After & Q (10) & 0.541 & 16.694 & 3.8493 \\
\hline AR (1) & & {$[0.763]$} & {$[0.081]$} & {$[0.146]$} \\
\hline \multirow{9}{*}{-GARCH $(1,1)$} & $\mathrm{Q}^{2}(10)$ & 3.83 & 5.214 & 4.7121 \\
\hline & & {$[0.147]$} & [0.074] & [0.095] \\
\hline & LM (10) & 3.7604 & 5.1492 & 4.6537 \\
\hline & & [0.153] & {$[0.076]$} & [0.097] \\
\hline & $\mathrm{LM}^{2}(10)$ & 2.2806 & 4.6428 & 4.3199 \\
\hline & & [0.319] & [0.098] & [0.115] \\
\hline & AIC & -2337.25 & -2357.68 & -2364.87 \\
\hline & BIC & -2316.71 & -2333.04 & -2340.23 \\
\hline & Log-L & 1173.62 & 1184.84 & 1188.43 \\
\hline
\end{tabular}

Figures in the square brackets are p-values

For each volatility model, we specify the mean equation model as follows:

$$
\mathrm{Rt}=\mu+\sum_{\mathrm{k}=1}^{\mathrm{K}} \phi_{\mathrm{k}} \mathrm{R}_{\mathrm{t}-\mathrm{k}}+\varepsilon_{\mathrm{t}}
$$

where $R_{t}$ represents TSAI market return series, $\mu$ is the conditional mean of the series, $\varepsilon_{t}$ is the error component and assumed to follow one of following densities, normal, Student- $t$ or GED. The K in the mean equation is determined by optimizing the Akaike Information Criterion (AIC). According to AIC we found AR (1) model has a better ability to fit the TSAI return series. A quasi maximum likelihood estimation technique has been used to estimate the volatility models with aforementioned three underlying error distributions. Table 2, 4 and 6 presents the joint estimation results of AR (1) and the GARCH, EGARCH and GJR-GARCH second moments, respectively. The use of GARCH, EGARCH and GJR-GARCH models seem to be justified. All $\beta$ coefficients are significant at conventional levels. Moreover, the tail coefficients $\zeta$ are significant justifying the use of non-normal densities.
Table 4: Parameter estimation of AR (1)-EGARCH model

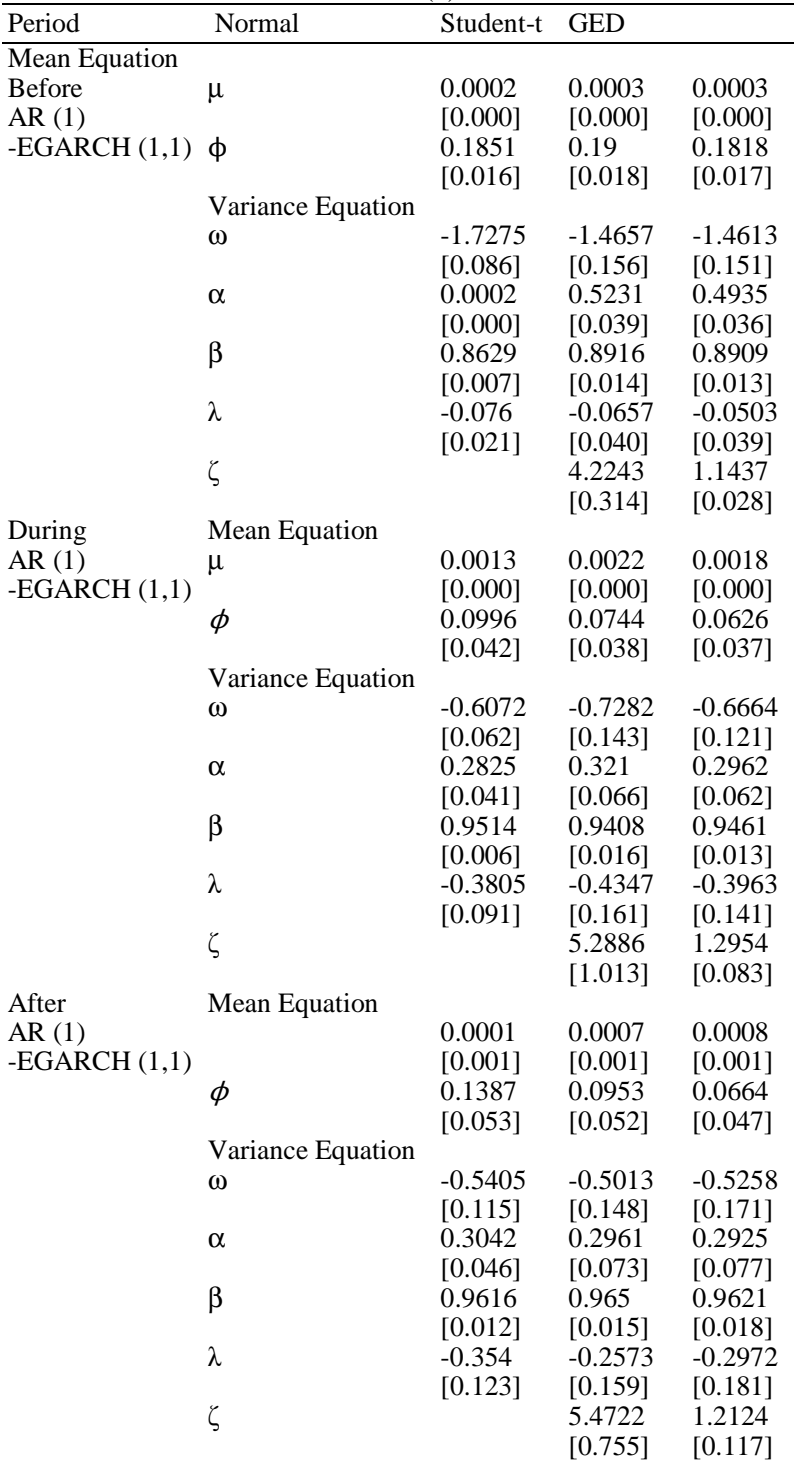

Figures in the square brackets are $p$-values

The leverage effect term $\lambda$ in the asymmetric models EGARCH and GJR-GARCH are statistically significant, furthermore with $\lambda$ negative sign in EGARCH model and non-zero in GJR-GARCH, as expected that negative (bad news) shocks imply a higher next period conditional variance than positive shocks of the same sign, indicating that the existence of leverage effect is observed in returns of the TSAI market index. Table 3, 5 and 7 shows that all models, symmetric and asymmetric seem to fit well describing the dynamics of the first two moments of the series as shown by the Ljung-Box statistics for the squared standardized residuals at lag 10 which are all nonsignificant at 5\% level. 
J. Math. \& Stat., 8 (1): 98-106, 2012

Table 5: Model diagnostics of AR (1)-EGARCH model

\begin{tabular}{|c|c|c|c|c|}
\hline Period & & Normal & Student-t & GED \\
\hline Before & $\mathrm{Q}(10)$ & 50.353 & 51.495 & 53.546 \\
\hline $\mathrm{AR}(1)$ & & {$[0.000]$} & {$[0.000]$} & {$[0.000]$} \\
\hline \multirow[t]{9}{*}{-EGARCH $(1,1)$} & $\mathrm{Q}^{2}(10)$ & 9.5326 & 5.5786 & 5.5246 \\
\hline & & [0.482] & [0.849] & {$[0.853]$} \\
\hline & LM (10) & 9.4642 & 5.5593 & 5.4724 \\
\hline & & {$[0.488]$} & {$[0.581]$} & {$[0.857]$} \\
\hline & $\mathrm{LM}^{2}(10)$ & 0.8017 & 0.3948 & 0.3954 \\
\hline & & [0.999] & {$[1.000]$} & {$[1.000]$} \\
\hline & AIC & -23041.6 & -23505.4 & -23447.7 \\
\hline & BIC & -23005.2 & -23462.9 & -23405.3 \\
\hline & $\log -\mathrm{L}$ & 11526.8 & 11759.7 & 11730.8 \\
\hline During & Q (10) & 15.896 & 13.928 & 15.641 \\
\hline AR (1) & & {$[0.103]$} & {$[0.176]$} & {$[0.110]$} \\
\hline \multirow[t]{9}{*}{-EGARCH $(1,1)$} & $\mathrm{Q}^{2}(10)$ & 7.9895 & 7.5062 & 8.1469 \\
\hline & & [0.629] & {$[0.677]$} & {$[0.614]$} \\
\hline & LM (10) & 7.94 & 7.5079 & 8.1181 \\
\hline & & {$[0.635]$} & {$[0.677]$} & {$[0.617]$} \\
\hline & $\mathrm{LM}^{2}(10)$ & 1.5936 & 1.249 & 1.5035 \\
\hline & & {$[0.998]$} & [0.999] & [0.999] \\
\hline & AIC & -4019.62 & -4067.53 & -4060.44 \\
\hline & BIC & -3991.81 & -4035.08 & -4028 \\
\hline & $\log -\mathrm{L}$ & 2015.81 & 2040.76 & 2037.22 \\
\hline After & $\mathrm{Q}(10)$ & 1.0915 & 2.1546 & 3.7363 \\
\hline $\mathrm{AR}(1)$ & & {$[0.579]$} & {$[0.340]$} & {$[0.154]$} \\
\hline \multirow[t]{9}{*}{-EGARCH $(1,1)$} & $\mathrm{Q}^{2}(10)$ & 1.8803 & 2.7184 & 2.5709 \\
\hline & & {$[0.391]$} & {$[0.257]$} & {$[0.276]$} \\
\hline & LM (10) & 1.8019 & 2.6268 & 2.4805 \\
\hline & & {$[0.406]$} & {$[0.269]$} & {$[0.289]$} \\
\hline & $\mathrm{LM}^{2}(10)$ & 0.3635 & 1.1822 & 1.0395 \\
\hline & & {$[0.834]$} & {$[0.554]$} & {$[0.595]$} \\
\hline & AIC & -2339.64 & -2355.33 & -2362.92 \\
\hline & BIC & -2314.99 & -2326.58 & -2334.17 \\
\hline & Log-L & 1175.82 & 1184.67 & 1188.46 \\
\hline
\end{tabular}

Figures in the square brackets are p-values

LM test for presence of ARCH effects at lag 10, indicates that the conditional heteroskedasticity exists when the test was performed on the pure return series (see Table 1) are removed. However, it is worth noting that standardized residuals in estimations using before crisis returns suffer from serial correlation. Regarding the densities, the symmetric distributions with heavy tails clearly outperform the conventional Gaussian distribution in all models considered in this study. As reported in Tables 3,5 and 7, the results of three selection criteria reveal that the Student's- $t$ conditional density is found to be the most favored distribution hypothesis for the standard GARCH and EGARCH models when before and during crisis period data is considered for estimations.
Table 6: Parameter estimation of AR (1)-GJR-GARCH model

\begin{tabular}{|c|c|c|c|c|}
\hline Period & & Normal & Student- $\mathrm{t}$ & GED \\
\hline & Mean equation & & & \\
\hline Before & $\mu$ & 0.0002 & 0.0003 & 0.0003 \\
\hline $\mathrm{AR}(1)$ & & {$[0.000]$} & {$[0.000]$} & {$[0.000]$} \\
\hline \multirow[t]{13}{*}{-GJR-GARCH $(1,1)$} & $\phi$ & 0.1803 & 0.184 & 0.1825 \\
\hline & & [0.019] & {$[0.018]$} & {$[0.018]$} \\
\hline & Variance Equation & & & \\
\hline & $\omega$ & 0.0001 & 0.0001 & 0.0001 \\
\hline & & {$[0.000]$} & {$[0.000]$} & [0.0000] \\
\hline & $\alpha$ & 0.2824 & 0.3052 & 0.2862 \\
\hline & & {$[0.017]$} & {$[0.041]$} & {$[0.036]$} \\
\hline & $\beta$ & 0.6304 & 0.655 & 0.6491 \\
\hline & & {$[0.023]$} & {$[0.025]$} & {$[0.026]$} \\
\hline & $\lambda$ & 0.0818 & 0.0675 & 0.0671 \\
\hline & & {$[0.023]$} & {$[0.048]$} & {$[0.043]$} \\
\hline & $\zeta$ & & 4.3418 & 1.1625 \\
\hline & & & {$[0.327]$} & {$[0.027]$} \\
\hline During & Mean Equation & & & \\
\hline \multirow{15}{*}{$\begin{array}{l}\text { AR }(1) \\
\text {-GJR-GARCH }(1,1)\end{array}$} & $\mu$ & 0.0013 & 0.0022 & 0.0001 \\
\hline & & {$[0.000]$} & {$[0.000]$} & {$[0.000]$} \\
\hline & $\phi$ & 0.0973 & 0.0716 & 0.0665 \\
\hline & & {$[0.041]$} & {$[0.038]$} & {$[0.037]$} \\
\hline & Variance Equation & & & \\
\hline & $\omega$ & 0.0001 & 0.0001 & 0.0001 \\
\hline & & {$[0.000]$} & {$[0.000]$} & {$[0.000]$} \\
\hline & $\alpha$ & 0.0445 & 0.0527 & 0.0527 \\
\hline & & [0.029] & {$[0.054]$} & {$[0.048]$} \\
\hline & $\beta$ & 0.8343 & 0.7901 & 0.816 \\
\hline & & [0.017] & {$[0.035]$} & {$[0.030]$} \\
\hline & $\lambda$ & 0.1726 & 0.2292 & 0.1814 \\
\hline & & {$[0.031]$} & {$[0.073]$} & {$[0.054]$} \\
\hline & $\zeta$ & & 5.2431 & 1.3122 \\
\hline & & & [0.019] & {$[0.085]$} \\
\hline After & Mean Equation & & & \\
\hline \multirow{15}{*}{$\begin{array}{l}\text { AR (1) } \\
\text {-GJR-GARCH }(1,1)\end{array}$} & $\mu$ & 0.0006 & 0.001 & 0.0011 \\
\hline & & {$[0.001]$} & {$[0.001]$} & {$[0.001]$} \\
\hline & $\phi$ & 0.1502 & 0.0959 & 0.0671 \\
\hline & & {$[0.056]$} & {$[0.050]$} & [0.046] \\
\hline & Variance Equation & & & \\
\hline & $\omega$ & 0.0001 & 0.0001 & 0.0001 \\
\hline & & {$[0.000]$} & {$[0.000]$} & {$[0.000]$} \\
\hline & $\alpha$ & 0.0892 & 0.0895 & 0.0879 \\
\hline & & {$[0.035]$} & {$[0.051]$} & {$[0.054]$} \\
\hline & $\beta$ & 0.832 & 0.8629 & 0.8598 \\
\hline & & [0.029] & {$[0.036]$} & [0.041] \\
\hline & $\lambda$ & 0.1327 & 0.073 & 0.0746 \\
\hline & & [0.059] & {$[0.063]$} & [0.069] \\
\hline & $\zeta$ & & 5.0054 & 1.172 \\
\hline & & & {$[0.513]$} & {$[0.113]$} \\
\hline
\end{tabular}

Figures in the square brackets are p-values

However, when we analyze after crisis period data, we discover that the GED appears to be the preferred conditional density for all models estimated in this study. 
Table 7: Model diagnostics of AR (1)-GJR-GARCH model

\begin{tabular}{lllll}
\hline Period & & Normal & Student-t & GED \\
\hline Before & Q (10) & 55.499 & 54.867 & 55.189 \\
AR (1) & & {$[0.000]$} & {$[0.000]$} & {$[0.000]$} \\
-GJR-GARCH (1,1) & Q $^{2}(10)$ & 3.6524 & 5.3984 & 4.7303 \\
& & {$[0.962]$} & {$[0.863]$} & {$[0.908]$} \\
& LM (10) & 3.6949 & 5.7449 & 4.9539 \\
& & {$[0.960]$} & {$[0.836]$} & {$[0.894]$} \\
& LM $^{2}(10)$ & 0.2014 & 0.2472 & 0.2297 \\
& & {$[1.000]$} & {$[1.000]$} & {$[1.000]$} \\
& AIC & -23086.8 & -23524.2 & -23469.5 \\
During & BIC & -23050.4 & -23481.7 & -23427.1 \\
AR (1)-GJR & Log-L & 11549.4 & 11769.1 & 11741.7 \\
-GARCH(1,1) & Q (10) & 14.737 & 12.714 & 14.101 \\
& & {$[0.142]$} & {$[0.240]$} & {$[0.168]$} \\
& Q ${ }^{2}(10)$ & 6.1973 & 5.4348 & 6.1507 \\
& & {$[0.798]$} & {$[0.860]$} & {$[0.802]$} \\
& LM (10) & 6.1889 & 5.5733 & 6.2217 \\
& & {$[0.799]$} & {$[0.849]$} & {$[0.796]$} \\
& LM ${ }^{2}(10)$ & 1.4882 & 1.1595 & 1.532 \\
& & {$[0.999]$} & {$[0.999]$} & {$[0.998]$} \\
After & AIC & -4021.85 & -4068.84 & -4061.83 \\
AR (1) & BIC & -3994.05 & -4036.39 & -4029.39 \\
-GJR-GARCH (1,1) & Q ${ }^{2}(10)$ & 2.3169 & 4.1621 & 3.7625 \\
& & {$[0.314]$} & {$[0.125]$} & {$[0.152]$} \\
& Log-L & 2016.93 & 2041.42 & 2037.91 \\
& LM (10) & 2.2463 & 4.1011 & 3.7072 \\
& & {$[0.325]$} & {$[0.128]$} & {$[0.157]$} \\
& LM ${ }^{2}(10)$ & 0.4914 & 2.0262 & 1.8747 \\
& & {$[0.782]$} & {$[0.363]$} & {$[0.392]$} \\
& AIC & -2339.56 & -2356.99 & -2364.14 \\
& BIC & -2314.92 & -2328.25 & -2335.39 \\
& Log-L & 1175.78 & 1185.5 & 1189.07 \\
\hline
\end{tabular}

Figures in the square brackets are p-values

Table 8: The Impact of Bad News

\begin{tabular}{|c|c|c|c|c|c|}
\hline GED & Student- $\mathrm{t}$ & Normal & Period & Model & \\
\hline 1.0503 & 1.0657 & 1.076 & Before crisis & $\mathrm{AR} \quad$ (1) & + \\
\hline \multicolumn{6}{|c|}{ EGARCH } \\
\hline 1.3963 & 1.4347 & 1.3805 & During crisis & & \\
\hline 1.2972 & 1.2573 & 1.354 & After crisis & & \\
\hline
\end{tabular}

Table 9: Volatility Persistence

\begin{tabular}{lllll}
\hline Model & Period & Normal & Student-t & GED \\
\hline AR (1) & Before crisis & 0.9613 & 0.9951 & 0.9696 \\
+ GARCH & During crisis & 0.991 & 0.9995 & 0.9873 \\
& After crisis & 0.9983 & 1.0000 & 0.9952 \\
AR (1) & Before crisis & 0.8629 & 0.8916 & 0.8909 \\
+EGARCH & During crisis & 0.9514 & 0.9408 & 0.9461 \\
& After crisis & 0.9616 & 0.965 & 0.9621 \\
AR (1) & Before crisis & 0.9537 & 0.9939 & 0.9688 \\
+GJR-GARCH & During crisis & 0.9652 & 0.9575 & 0.9595 \\
& After crisis & 0.9876 & 0.9888 & 0.9851 \\
\hline
\end{tabular}

As, is typical of volatility model estimates for financial asset returns data, the sum of the coefficients on the lagged squared error $(\alpha)$ and the lagged conditional variance $(\beta)$ are close to unity, which is a measure of volatility persistence. Table 9 , indicate that volatility persistence were high during and after the crises, this implies that shocks to the conditional variance well be highly persistent indicating that large changes and small changes tend to be followed by small changes, this mean volatility clustering is observed in TSAI financial returns series. The results are consistent with previous studies (Mohd et al. (2007) and Nor et al (2009). Moreover, as presented in Table 8, the effects of bad news seem to be much higher during the crisis compared to the rest of the periods.

\section{CONCLUSION}

Once the volatility becomes predictable, it has great attention for both practitioners and academicians. Volatility became an essential requirement for investors who are concerned about volatility (uncertainty) and risks on their investment portfolio.

In this study, firstly, we have examined the volatility of the Saudi's stock price index (TSAI). Secondly, we estimate the alternative GARCH-type models (symmetric and asymmetric GARCH Models). The comparisons were focused on two different aspects: the difference between symmetric and asymmetric GARCH (i.e., GARCH versus EGARCH and GJR-GARCH) and the difference between normal tailed symmetric, heavy-tailed symmetric distributions (Student $-t$ ) and both heavy-tailed and asymmetric distributions (GED) for estimating TSAI stock market index return volatility. We discover that all coefficients of the volatility models were significant. The persistent measure $\alpha+\beta$, in the periods of during and after crisis and under different distribution assumptions have higher persistent than before crisis. Moreover, the estimation results reveal the existence of leverage effects in EGARCH and GJR-GARCH models.

However, the comparison between models with each density (normal versus non-normal) was that, according to AIC and BIC measures used for volatility model selection, the GJR-GARCH model with Student$t$ distribution provides the best sample estimation for both periods before and during crisis, which clearly outperform the symmetric models. On the other hand, GARCH with GED performs very well the dataset we have investigated for the period after crisis .Our results show that, non-normal distributions provide better in-sample estimation results than the normal distribution.

\section{REFERENCES}

Alkhathlan, K. and S. Prabakaran, 2009. Memory effects on Saudi Arabian stock market-empirical evidence. Enterprise Risk Management, 1: 1-21. 
Bera, A.K. and M.L. Higgins, 1993. ARCH models: Properties, estimation and testing. J. Econ. Surv., 7: 305-366. DOI: $\quad$ 10.1111/j.14676419.1993.tb00170.x

Black, F., 1976. Studies of stock price volatility changes. Proceedings of the American Statistical Association of the Business and Economics Section Meetings, (BESM' 76), USA., pp: 177181.

Bollerslev, T., 1986. Generalized autoregressive conditional heteroskedasticity. J. Econ., 31: 307327. DOI: 10.1016/0304-4076(86)90063-1

Box, G.E.P. and G.M. Jenkins, 1994. Time Series Analysis: Forecasting and Control. 3rd Edn., Pearson Education India, Englewood Cliffs, ISBN10: 0130607746 pp: 592.

Daly, K., 2008. Financial volatility: Issues and measuring techniques. Phys. A: Stat. Mecha. Appli., 387: 2377-2393. DOI: 10.1016/j.physa.2008.01.009

Engle, R.F., 1982. Autoregressive Conditional Heteroscedasticity with Estimates of the Variance of United Kingdom Inflation. Econometrica, 50: 987-1008.
Glosten, L.R., R. Jagannathan and D.E. Runkle, 1993. On the relation between the expected value and the volatility of the nominal excess return on stocks. J. Finan., 48: 1779-1801.

Jarque, C.M. and A.K. Bera, 1987. A test for normality of observations and regression residuals. Int. Stat. Rev., 55: 163-172.

Morimune, K., 2007. Volatility models. Japanese Econ. Rev., 58: 1-23.

Mohd, N., A.H. Shaari and A. Shamiri, 2007. Modeling and forecasting volatility of the Malaysian and the Singaporean stock indices using asymmetric GARCH models and non-normal densities. Malaysian J. Math. Sci., 1: 83-102.

Nelson, D.B., 1991. Conditional heteroskedasticity in asset returns: A new approach. Econometrica, 59: 347-370.

Nor, A.H.S.M., A. Shamiri and Z. Isa Shamiri, A., M.S.N. Abu Hassan and I. Zaidi, 2009. Comparing the accuracy of density forecasts from competing GARCH models. Sains Malaysiana, 38: 109-118. 